\title{
Titanium Elastic Nailing System (TENS) for Tibia Fractures in Children: Functional Outcomes and Complications
}

\author{
Kapil Mani KC, ${ }^{1}$ Parimal Acharya, ${ }^{1}$ Arun Sigdel \\ 'Department of Orthopedics, Civil Service Hospital, Minbhawan, Kathmandu, Nepal.
}

\section{ABSTRACT}

Introduction: Closed reduction and cast application is still regarded as first line treatment for pediatric tibial fractures. Over the past few decades, management of pediatric tibial fractures has shifted more towards operative intervention because of quicker recovery, shorter rehabilitation period, less immobilization, lack of stiffness of adjoining joints, and less psychological impact to the children. Flexible intramedullary nails not only fulfill the above advantage but also maintain alignment and rotation.

Methods: This was a retrospective study of pediatric tibial fractures fixed with two titanium elastic nails through proximal ends of bones. Alignment of fracture, any infection, delayed union, non union, limb length discrepancy, motion of knee joint, and fracture union time were measured during follow-up examination.

Results: Forty-five patients were enrolled into the study out of which $28(62.2 \%)$ were male and 17 $(37.8 \%)$ were female. Average age of patient was $9.48 \pm 2.17$ years and average time taken to heal the fractures (both clinical and radiological) was $11.17 \pm 2.81$ weeks. There were $2(4.4 \%)$ of malunion, 4 $(8.8 \%)$ of delayed union, $3(6.6 \%)$ of limb shortening, 2 (4.4\%) of limb lengthening, 6 (13.6\%) of nail prominence and skin irritation, $2(4.4 \%)$ of superficial infection at nail entry site and one case of refracture.

Conclusions: Titanium elastic nail fixation is a simple, easy, rapid, reliable and effective method for management of pediatric tibial fractures in patients with operative indications. There may be the chances of complication following the TENS in tibia but these are avoidable as well as manageable with careful precautions.

Keywords: complications; functional outcomes; tibia fractures.

\section{INTRODUCTION}

Tibia fractures in children are third most common long bone fractures after forearm and femoral fractures. ${ }^{1}$ Closed reduction and cast application is still regarded as first line treatment for pediatric tibial fractures provided the appropriate indications are present. ${ }^{2,3}$ Historically operative treatment has rarely been indicated in tibial fractures in children. ${ }^{4}$ Over the past few decades, management of pediatric tibial fractures has shifted more towards operative intervention because of quicker recovery, shorter rehabilitation period, less

Correspondence: Dr. Kapil Mani KC, Department of Orthopedics, Civil Service Hospital, Minbhawan, Kathmandu, Nepal. Email: drkapil2007@yahoo.com, Phone: +977-9841244502. 
immobilization, lack of stiffness of adjoining joints, and less psychological impact to the children. ${ }^{5,6}$

The aim of our study is to evaluate the functional outcomes, possible complications after surgery including recent literature reviews of tibia fractures in children fixed with titanium elastic nails.

\section{METHODS}

This was a retrospective analytical study performed in Civil Service Hospital, Minbhawan from August 2011 to July 2016. Consent was taken from parents of all patients and ethical approval was taken from the Institutional Review Board of our hospital. Diaphyseal tibia fractures associated with compartment syndrome, floating knee, multiple long bone fractures, multisystem injuries, head injury or cerebral palsy, unstable fractures, grade I or II compound fractures, failed closed reduction in which adequate alignment cannot be attained or maintained were included in the study. Tibia fractures in patients of age less than 5 years and more than 14 years, grade III compound fractures, fractures associated with infected wound, those treated with conservative treatment with acceptable alignment, fractures associated with severe comminution, massive bone loss, severe osteopenia and fractures within four centimeters of the knee joint or within three centimeters of the ankle joint were excluded from the study.

All-together forty-five patients were enrolled into the study. All patients were operated under general anesthesia. The appropriate size of nail was calculated by using the Flynn's formula i.e. nail diameter $=0.4 \mathrm{x}$ Narrowest diameter of medullary canal. The nail was pre-countered manually into $C$ shape configuration for intramedullary three point fixation. The tip of nail was bent to 45 degree for easy passage through the fracture site. Around $2 \mathrm{~cm}$ of incision was given either medial or lateral side of proximal leg and entry point was made 1.5 to $2 \mathrm{~cm}$ distal to the physis with the help of owl. Now the pre-countered nail tip was inserted into the medullary canal and advanced to the fracture site. Once the nail reached to the fracture site close reduction was done and nail advanced distally through the fracture site. The proper intramedullary position of the nail was checked in $\mathrm{C}$-arm both in antero-posterior and lateral views. Another nail was inserted by similar method as described before. Both the nails were advanced distally till the tips were just proximal to the distal tibial physis. We left around $1 \mathrm{~cm}$ of nail outside the cortex proximally for removal, however unburied portion of nail was not bent because it may cause irritation of skin and bursitis at entry site of nail. It is important that both the nails are of same size to avoid differential loading in opposite cortices which may lead to angular deformity. Long leg posterior slab was applied at the time of surgery. After three weeks posterior slab was removed and patients were advised to walk with partial weight bearing on the affected limb.

Patients were evaluated at two weeks, six weeks, three months, six months and one year after surgery to observe the alignment of fracture, any infection, delayed union, nonunion, limb length discrepancy, motion of knee joint, and fracture union time. Orthopedic registrars as well as consultants in outpatient department measured all these parameters. Final limb length discrepancy, fracture alignment and range of movement were calculated at the time of fracture union. Alignment of fracture was assessed by drawing lines on X-ray films and measured with a goniometer. Limb length discrepancy was assessed by measuring both limbs from anterior superior iliac spine to medial malleolus in supine position. Any difference of length in the fractured limb as compared to the normal one was taken as limb length discrepancy. Range of movement of knee joint was assessed by passive extension and flexion of knee joint and the angle was measured with a goniometer. Delayed union and nonunion were assessed on the basis of clinical and radiological union. Radiological union is defined as the appearance of a mature callus at least on 3 out of 4 planes and clinical union as no pain on movement of the fracture ends. ${ }^{15}$ All of the data were tabulated in Microsoft Excel Programme and results were interpreted as mean \pm standard deviation and simple percentage also.

\section{RESULTS}

Demographic profile of patients, fracture pattern and mechanism of injury was mentioned in table 1. Average age of patient in our study was $9.48 \pm 2.17$ years and average time taken to heal the fractures (both clinical and radiological) was $11.17 \pm 2.81$ weeks. Complications encountered in our study were shown in table 2 while numbers of patients with different surgical indications were mentioned in table 3.

\begin{tabular}{|lc|}
\hline $\begin{array}{l}\text { Table 1. Demographic patterns of patients and } \\
\text { fractures. }\end{array}$ & $\mathbf{n}(\%)$ \\
\hline Parameters & $28(62.2 \%)$ \\
Gender & $17(37.8 \%)$ \\
Male & \\
Female & $20(44.4 \%)$ \\
Side & $25(55.6 \%)$ \\
Right & \\
Left & $12(26.7 \%)$ \\
Mechanism of injury &
\end{tabular}


KC al. Titanium Elastic Nailing System for Tibia Fractures in Children: Functional Outcomes and Complications

\begin{tabular}{|ll|} 
Motor Vehicle injury & $9(20 \%)$ \\
Fall from height & $8(17.8 \%)$ \\
Sports related injury & $7(15.5 \%)$ \\
Motor bike injury & $9(20 \%)$ \\
Pattern of fracture & \\
Transverse fractures & $21(46.7 \%)$ \\
Oblique fractures & $11(24.4 \%)$ \\
Spiral fractures & $7(15.6 \%)$ \\
Comminuted fractures & $6(13.3 \%)$ \\
\hline
\end{tabular}

Table 2. Showing the complications after operative intervention.

\begin{tabular}{ll|}
\hline Parameters & Complications n (\%) \\
Malunion & $2(4.4 \%)$ \\
Delayed union & $4(8.8 \%)$ \\
Nonunion & - \\
Limb shortening & $3(6.6 \%)$ \\
Limb lengthening & $2(4.4 \%)$ \\
$\begin{array}{l}\text { Nail prominence } \\
\text { Irritation }\end{array}$ & $6(13.3 \%)$ \\
$\begin{array}{l}\text { Superficial infection at entry } \\
\text { site }\end{array}$ & $2(4.4 \%)$ \\
Osteomyelitis & - \\
Re-fracture & $1(2.2 \%)$ \\
Compartment syndrome & - \\
\hline
\end{tabular}

Table 3. Showing the number of patients with different surgical indications.

\begin{tabular}{|c|c|}
\hline Surgical indications & n (\%) \\
\hline $\begin{array}{l}\text { 1.Tibia fractures with multiple long } \\
\text { bone fractures }\end{array}$ & $9(20 \%)$ \\
\hline 2. Tibia fractures with head injury & $7(15.5 \%)$ \\
\hline 3.Grade I or II tibia fractures & $11(24.4 \%)$ \\
\hline $\begin{array}{l}\text { 4. Failed closed reduction with } \\
\text { unacceptable alignment }\end{array}$ & $12(26.6 \%)$ \\
\hline 5. Unstable tibia fractures & $6(13.3 \%)$ \\
\hline 6. Those with compartment syndrome & - \\
\hline
\end{tabular}

\section{DISCUSSION}

The current indications for operative treatment include compound fractures, fractures associated with floating knees, multiple long bones fractures, multisystem injuries, fractures associated with compartment syndrome, children with spasticity like cerebral palsy or head injury and unstable fractures in which appropriate alignment cannot be attained or maintained. ${ }^{7-10}$ Commonly used methods for operative treatment include percutaneous metallic pins or bio-absorbable pins, open reduction and internal fixation with plates and screws, external fixators, flexible intramedullary titanium or stainless steel nails or in some cases intramedullary Steinmann pins..$^{4,11,12}$

Intramedullary flexible nails not only maintain alignment but also adjust the rotation of limb while treating the fractures. In addition to appropriate stability, flexible nails provide some amount of elasticity and micro-motion at fracture site that stimulates the callus formation and ultimately accelerates the fracture union. Small incision made during surgical treatment reduces significantly the probability of infection. ${ }^{13,14}$ Tibial diaphyseal fractures are one of the common fractures in pediatric age group. Most of these fractures have traditionally been treated with conservative measures with satisfactory results. ${ }^{16}$ Closed reduction and application of cast is a successful treatment in tibia fractures with very few complications. ${ }^{2,17}$ Conservative treatment is particularly indicated in stable tibia fractures whether fibula is intact or not. ${ }^{18}$

The ideal implant to treat the tibial or femoral fractures in children should be a load sharing device maintaining the length and alignment until appearances of callus at fracture site while allowing the early mobilization and without endangering the tibial physis at entry point. ${ }^{19}$ Ender nails work on the principle of simply filling the medullary canal of bone while TENs work by balancing the forces between two flexible nails inside the medullary canal acting in opposite direction. To achieve the appropriate balance, diameter of the nail should be $40 \%$ or more of narrowest diameter of medullary canal as well as nails should assume double ' $C$ ' shaped construct. In addition they should have same level of entry points at bone both medially and laterally and have similar smooth curves. ${ }^{20,21}$

The most common complication related to elastic stable intramedullary nail (ESIN) or TENS is nail prominence and irritation at entry site. There were $6(13.3 \%)$ cases of nail prominence, skin irritation or bursa formation in our study. Nail prominence may lead to more serious complications like superficial or deep infection, skin breakdown, bursitis, effusion and stiffness at adjacent joint, reoperation for trimming or nail advancement, and premature implant removal with subsequent risk of re-fracture. ${ }^{22}$ The worst complication is extension of infection to diaphysis causing osteomyelitis. ${ }^{23}$ The prevalence of skin irritation by nail varies from $3 \%$ to $52 \%$, femur being the most commonly affected site. The earlier version regarding the bending of nails and leaving them prominent for easy removal have been modified. ${ }^{24}$ For tibial TENS or ESIN Sankar et $\mathrm{al}^{10}$ advised that $1.5 \mathrm{~cm}$ of nail should be outside the bony cortex. It should be parallel to the proximal metaphysis and should not be bent the protruded portion of nail. 


\begin{tabular}{|lll|}
\hline $\begin{array}{l}\text { Table 4. Showing the acceptable alignment of tibia } \\
\text { fracture in children }\end{array}$. \\
\hline Patient Age & $<8$ Years & $\geq 8$ Years \\
Valgus & 5 degrees & 5 degrees \\
Varus & 10 degrees & 5 degrees \\
Angulation anterior & 10 degrees & 5 degrees \\
Posterior angulation & 5 degrees & 0 degrees \\
Shortening & 10 mm & 5 mm \\
Rotation & 5 degrees & 5 degrees \\
\hline
\end{tabular}

There were two cases of malunion in our study. One case with 9 degree of anterior angulation and another case with 10 degree of varus angulation. Normal range of acceptable alignment and limb length discrepancy after tibia fractures in children was mentioned in table 4. Rotational mal-alignment was not noticed because of extreme care taken while adjusting the limb position during surgery. Even though malalignment is not so common in tibia fracture fixed with TENS ${ }^{12}$, Goodwin et $\mathrm{al}^{26}$ reported two cases with angular deformity of 10 degrees each. Tibial TENS is technically difficult because of eccentric position of tibia in leg muscles and triangular cross section of medullary cavity, both of which makes prone to recurvatum deformity when nails are passed with their tension and convexity directed posteriorly. ${ }^{22,27}$ In such circumstances, tip of flexible nails should be directed posteriorly to counteract the recurvatum force. Lascombes et $\mathrm{al}^{22}$ recommended that nail tip should be in valgus position to counteract the varus force of intact fibula in case of isolated tibia fractures. Body weight even more than $49 \mathrm{~kg}$ does not seem to be an important predictor for malunion in tibia fractures fixed with TENS. ${ }^{10}$

There were $4(8.8 \%)$ cases of delayed union and no case of nonunion in our study. When there is no callus formation at 12 weeks after surgery it is assumed as delayed union and no osseous healing at six months after surgery is assumed as nonunion. Both delayed union and nonunion are uncommon after ESIN in long bones of lower limbs. However, there could be a nonunion or delayed union when tibia is fractured by severe direct injury, even if ESIN is used. ${ }^{23}$ Tibia fractures treated by the TENS or ESIN sometimes result in hypertrophic nonunion when fibula is intact or heals quickly so that there is slight distraction at fracture site. ${ }^{23,27}$ This type of nonunion is treated by either 1 $\mathrm{cm}$ of fibular resection or rigid intramedullary nailing. Similarly infection at fracture site because of open wound after ESIN or TENS results in delayed union or nonunion. Srivastava et $\mathrm{al}^{28}$ mentioned five cases of delayed union and two cases of nonunion in open tibia fractures fixed with ESIN.

There was not a single case of compartment syndrome observed in our study. However compartment syndrome has been reported with tibia or femur fractures fixed with ESIN or $\mathrm{TENS}^{23}$. Sankar et $\mathrm{al}^{10}$ reported four cases of compartment syndromes and three cases of impending compartment syndromes during the course of treatment which are treated by fasciotomy at the time of index surgery. Shital $\mathrm{N}$ Parikh et $\mathrm{al}^{23}$ noted that patients treated with greater use of fluoroscopy and longer operative time were increased risk of compartment syndrome because of multiple attempts at fracture reduction and possible soft tissue injury while passing the nail at multiple times. Compartment syndrome diagnosed during conservative treatment is managed by fasciotomy and ESIN which helps in fracture stabilization and wound care. When compartment syndrome is diagnosed after ESIN, nails protect fracture displacement during and after fasciotomy. ${ }^{26}$ Excessive fracture site manipulation should be avoided if possible. Authors advise to follow "ten minute rule" which means if we are unable to pass the nail through fracture site in ten minutes open reduction should be prefered. ${ }^{29}$

None of the patients in our series required any secondary surgical intervention or readmission following discharge, except for nail removal. Limb shortening was observed in 3 cases $(6.6 \%)$ and limb lengthening was found in 2 cases $(4.4 \%)$ for which we believe that a longer followup duration is required to determine its persistence or correction. Usually shortening may occur because of comminuted fractures and lengthening may be due to stimulation of physis associated with hyper-vascularity during fracture healing. ${ }^{21}$ No major complications were encountered but few minor complications like superficial infection in $2(4.4 \%)$ cases, irritation and bursa formation at the site of nail entry $6(13.3 \%)$ and one case of re-fracture were noted in our study.

Improper surgical techniques, difficult fracture reduction and forceful nail insertion can cause iatrogenic comminution at fracture site that leads to fracture instability and change of intraoperative management. Stainless steel has greater propensity of causing iatrogenic fracture as compared to the titanium nail because of greater rigidity of nail. ${ }^{22}$ Shital N Parikh ${ }^{23}$ advised increased bent at tip of nail to facilitate the passage of nail through fracture site without perforation of opposite cortex. If the nail does not advance, it should be withdrawn, rotated and reinserted. Still the nail does not advance, smaller size nail should be tried. 
KC al. Titanium Elastic Nailing System for Tibia Fractures in Children: Functional Outcomes and Complications

\begin{tabular}{|c|c|c|c|}
\hline Variables & Excellent & Satisfactory & Poor \\
\hline $\begin{array}{l}\text { Limb Length } \\
\text { Inequality }\end{array}$ & $<1.0 \mathrm{~cm}$ & $<2.0 \mathrm{~cm}$ & $>2.0 \mathrm{~cm}$ \\
\hline $\begin{array}{l}\text { Mal- } \\
\text { alignment }\end{array}$ & 5 degrees & 10 degrees & $\begin{array}{l}>10 \\
\text { degrees }\end{array}$ \\
\hline Pain & None & None & Present \\
\hline $\begin{array}{l}\text { Other } \\
\text { complications }\end{array}$ & None & $\begin{array}{l}\text { Minor and } \\
\text { resolved }\end{array}$ & $\begin{array}{l}\text { Major and } \\
\text { lasting } \\
\text { morbidity }\end{array}$ \\
\hline
\end{tabular}

Outcome was graded by Flynn's criteria ${ }^{30}$ as excellent, satisfactory and poor. In our study we achieved $90 \%$ excellent outcome, $10 \%$ satisfactory and no poor outcome.

\section{CONCLUSIONS}

In conclusion, TENS is a simple, easy, rapid, reliable and effective method for management of pediatric tibial fractures between the age of 5 to 14 years, with shorter operative time, lesser blood less, shorter hospital stay, and reasonable time to bone healing. There may be the chances of complication following the TENS in tibia but these are avoidable as well as manageable with careful precautions taken during surgery.

\section{Conflict of Interest: None.}

\section{REFERENCES}

1. Settera KJ, Palominob KE. Pediatric tibial fractures: current concepts. Curr Opin Pediatr. 2006;18:30-5.

2. Yang JP, Letts RM. Isolated fractures of the tibia with intact fibula in children: a review of 95 patients. J Pediatr Orthop. 1997;17(3):347-51.

3. Canavese Federico, Botnari Alexei, Andreacchio Antonio, Marengo Lorenza Samba, Antoine Dimeglio Alain, Pereira Bruno et al. Displaced Tibial Shaft Fractures With Intact Fibula in Children: Nonoperative Management Versus Operative Treatment With Elastic Stable Intramedullary Nailing. Journal of Pediatric Orthopaedics. 2016;36(7):667-72

4. Vallamshetla VR, De Silva U, Bache CE, Gibbons PJ. Flexible intramedullary nails for unstable fractures of the tibial in children. An eight-year experience. J Bone Joint Surg Br. 2006;88(4):536-40

5. Hossein Aslani, Ali Tabrizi, Ali Sadighi, Ahmad Reza Mirblok. Treatment of Open Pediatric Tibial Fractures by External Fixation Versus Flexible Intramedullary Nailing: a Comparative Study. Arch Trauma Res. 2013;2(3):108-12.

6. Ping Liu, Zuo Wei, You-Xiu Wei, Wen-Xiao Sun, He-Wei $\mathrm{Li}$, Song Huang et al. Treatment of children's shaft fracture of tibia and fibula with ESIN fixation. Open Journal of Pediatrics. 2011;1:9-11.

7. Griffet J, Leroux J, Boudjouraf N, Abou-Daher A, El Hayek T Elastic stable intramedullary nailing of tibial shaft fractures in children. J Child Orthop. 2011;5(4):297-304.

8. Mark G Swindells, Rajan RA. Elastic intramedullary nailing in unstable fractures of the paediatric tibial diaphysis: a systematic review. J Child Orthop. 2010;4:45-51.

9. Kubiak EM, Egal KA, Scher D. Operative treatment of tibial fractures in children: are elastic stable intramedullary nails an improvement over external fixation? J Bone Joint Surg Am. 2005;87:1761-8.
10. Sankar WN, Jones KJ, David Horn B, Wells L. Titanium elastic nails for pediatric tibial shaft fractures. J Child Orthop. 2007;1:281-6.

11. Salem KH, Lindemann I, Keppler P. Flexible intramedullary nailing in pediatric lower limb fractures. J Pediatr Orthop. 2006;26:505-9.

12. O'Brien T, Weisman DS, Ronchetti P, Piller CP, Maloney M. Flexible titanium nailing for the treatment of the unstable pediatric tibial fracture. J Pediatr Orthop. 2004;24(6):601-9.

13. Furlan D, Pogorelic Z, Biocic M, Juric I, Budimir D, Todoric J, Susnjar DT et al. Elastic stable intramedullary nailing for pediatric long bone fractures: experience with 175 fractures. Scandinavian Journal of Surgery. 2011;100:208-15.

14. P R Onta, P Thapa, K Sapkota, N Ranjeet, A Kishore, M Gupta. Outcome of Diaphyseal Fracture of Tibia Treated with Flexible Intramedullary Nailing in Pediatrics Age Group; A Prospective Study. American Journal of Public Health Research. 2015;3(4A):65-8.

15. Whelan DB, Bhandari M, McKee MD. Interobserver and intraobserver variation in the assessment of the healing of tibial fractures after intramedullary fixation. J Bone Joint Surg Br. 2002;84:15-8.

16. Briggs TW, Orr MM, Lightowler CD. Isolated tibial fractures in children. Injury. 1992;23(5):308-10.

17. Shannak AO. Tibial fractures in children: follow-up study. J Pediatr Orthop 1988;8:306-310

18. Wessel L, Seyfriedt CS, Hock S, Waag KL. Pediatric tibial fractures: is conservative therapy still currently appropriate? [Article in German]. Unfallchirurg. 1997;100(1):8-12.

19. Buechsenschuetz KE, Mehlman CT, Shaw KJ, Crawford AH, Immerman EB. Femoral shaft fractures in children: Traction and casting versus elastic stable intramedullary nailing. J Trauma. 2002;53- 5:914-21. 
20. Pradeep Choudhari, Sachin Chhabra, VivekKiyawat. Evaluation of Results of Titanium Elastic Nailing System in Paediatric Lower Extremity Fractures of Long Bones. Journal of Evolution of Medical and Dental Sciences. 2014;3(72):15303-9.

21. Gamal El-Adal, Mohamed F Mostafa, Mohamed A Khalil, Ahmed Enan. Titanium elastic nail fixation for pediatric femoral and tibial fractures. Acta Orthop Belg. 2009;75:512-20.

22. Shital N Parikh, Viral VJain, Jaime Denning, Junichi Tamai, Charles T Mehlman, James J McCarthy et al. Complications of Elastic Stable Intramedullary Nailing in Pediatric Fracture Management. J Bone Joint Surg Am. 2012;94:e184(1-14).

23. Lascombes P. Flexible intramedullary nailing in children: the Nancy University Manual. Heidelberg: Springer; 2009.

24. Barry M, Paterson JMH. Flexible intramedullary nails for fractures in children. J Bone Joint Surg [Br]. 2004;86-B:947-53.

25. Stephen D Heinrich, James F Mooney. Fracture of shaft of the tibia and fibula. In: Beaty, James H.; Kasser, James R (eds) Rockwood and Wilkins Fractures in Children, 7th Edition. Lippincott Williams \& Wilkins, Philadelphia. 2010. p. 949-50.
26. Goodwin RC, Gaynor T, Mahar A, Oka R, Lalonde FD. Intramedullary flexible nail fixation of unstable pediatric tibial diaphyseal fractures. J Pediatr Orthop 2005;25(5):570-6.

27. Slongo TF. Complications and failures of the ESIN technique. Injury 2005;36 Suppl. 1:A78-85.

28. Srivastava AK, Mehlman CT, Wall EJ, Do TT. Elastic stable intramedullary nailing of tibial shaft fractures in children. J Pediatr Orthop. 2008 Mar;28(2):152-8.

29. Parikh SN, Wells L, Mehlman CT, Scherl SA. Management of fractures in adolescents. J Bone Joint Surg Am. 2010;92(18):2947-58.

30. Flynn JM, Luedtke LM, Theodore J, Ganley TJ, Dawson J, Davidson RS et al. Comparison of titanium elastic nails with traction and a spica cast to treat femoral fractures in children. J Bone Joint Surg Am. 2004;86:770-7. 